which fertilize the ova within $4 \mathrm{~h}$, that is, become func. tionally capacitated, are those which have lost their acrosomes. Rather, the capacitated sperm must be those in a stage earlier than this terminal statc. Electron mierographs have shown that rabbit and hamster sperm in the female genital tract undergo a gradual swelling of the acrosomal cap, followed by a patchy vesiculation between the outer acrosomal membrane and the plasma membrane as the sperm enters the zona pellucida of the ovum $^{2,6,2}$. One or more such subtle changes, invisible by the light microscope, may be the physical basis of capacitation.

Some sperm were capacitated in medium 199 alone, so that follicular factors do not seorn to be absolutely essential for the capacitation process; although they may be required to accelerate it, or render it moro efficient. We do not know whether this effect occurs by direct action on the sperm, or indirectly by provision of the appropriate environment for an endogenous process. We have observed that sperm collected directly from the epididymis exhibit fairly progressive movement. After $6 \mathrm{~h}$ in medium 199 , or in follicular fluid, this changes to a bobbing motion of the head. This type of movement is clearly suitable, and perhaps also critical, for zona penetration. Further studies are in progress to correlate this change with the capacitation procoss.

R. B. L. GWATKIN

Merck Instituto for Therapeutic Research, O. F. ANDERSEN

Rahway, New Jersey.

Received Angust 26; revised October 13, 1969.

${ }^{2}$ Austin, C. R., Int. J. Fertil.,12, 25 (1967).

${ }^{3}$ Hadek, R., Manmalian Fertilization: An Atlas of Ultrastructure (Academic Press, New York, 1969).

${ }^{3}$ Barros, C., and Austin, C. R., J. Exp. Zool., 166, 317 (1967).

- Yanagimachi, R., J. Reprod. Fert., 18, 275 (1969).

${ }^{5}$ Morgan, J. F., Morton, H. J., and Parker, R. C., Proe. Soc. Lxp. Biol. and Med, ${ }^{2}, 13$, 1 (1950).

'Barros, C., and Franklin, L. E., J. Cell Biol., 34, C13 (1967).

' Bedford, J. M., Amer. J. Anat., 123, 329 (1969).

\section{Gonadal Development and Reproductive Activity of the Cichlid Fish Tilapia leucosticta (Trewavas) in an Equatorial Lake}

ThE most important external factors that influence gonadal development and reproductive activity are daylength and temperature ${ }^{1}$. In temperate zones both factors show dramatic changes in the annual cycle. In the tropics, daylength shows much less significant variation than it does in the temperate zones and temperatures are generally quite high throughout tho year. These variations are even less in the equatorial zone. The most prominent seasonally varying climatic feature is usually rainfall. Its influence on the reproductive activity of tropical fish has not been clearly determined.

Previous studies on the cichlid fishes of the genus Tilapia have failed to clarify the role of external factors (particularly rainfall) in their reproduction ${ }^{2-4}$ because of insufficient data. A study from January 1968 to April 1969 on the gonadal and reproductive pattern of $T^{\text {. }}$. leucosticta in an equatorial lake (Lake Naivasha, Kenya) has revealed marked seasonal fluctuation of temperature and sunshine in addition to those of rainfall. July and August are cold months (ocoasionally tomperatures are below $0^{\circ} \mathrm{C}$ ), dry and with least sunshine (computed as mean h/day of maximum sunshine from traces made by a Casella bimetallic actinograph). No brooding females were recovered in these months and both mature males and females had uniformly retarded gonads. Gonadal development and slight breeding activity followed the temperature and sunshine riso in September, though
November (with rainfall and poor sunshine) had reduced reproduction.

The period December to March is marked by high temperatures, no rainfall and a sustained rise in the mean hours of maximum sunshine. There is also a simultaneous rise of gonadal development uniformly in all the mature fish of both sexes. This culminates in a sharp annual peak of gonadal development in February and a subsequent one of breeding in late February to early March. Conditions of high temperature and practically no rainfall wcre repeated in 1968 and 1969 , but tho sumshine patterns were only available for $1969 \mathrm{in}$ this period. From weather data obtained before and during the study, the period December 1967 to mid-Fcbruary 1968 was particularly dry and had very high temperatures and almost certainly extended periods of maximum sunshino. This was reflected in a much higher peak of gonadal developmont in mid-February 1968 than was seen in February 1969. Peak breeding was noticed in late February and early March 1968, coincident with the onset of the rains. Subsequont heavy rains appear to have checked further gonadal development and breeding. In 1969, when con. ditions of relatively high temperatures and good sunshine prevailed to the end of April (when the study ended), peak breeding was again coincident with the start of the rains, but unusually poor rains resulted in a second peak of gonadal development and reproductive activity in late April 1969.

Good sunlight and high temperatures seem to be essential prerequisites of satisfactory gonadal development in $T$. leucosticta and breeding is stimulated bybut can certainly proceed without-rainfall. Thus Tilapia in equatorial ponds enjoying high intensities of both light and temperature have highly stimulated gonads ${ }^{5}$ and reproduce continuously ${ }^{5,6}$ without rainfall. This study supports the carlier suggestion that both light and temperature are critical in the gonadal development of Tilapia ${ }^{5}$. It nevertheless seems that in natural conditions (as against artificial pond eonditions) the onset of the rains coincides with the onset of peak breeding where light and temperature had previously stimulated gonadal development. The mechanism whereby the onsct of the rainfall can stimulate breeding in Tilapia or its adaptive significance remains unclear.

This work was supported by the Nuffield and Munitalp Foundations, War on Want and the Wellcome Trust. I acknowledge the cooperation of the Chief Fisheries Officer, Republic of Kenya, and thank Mr G. A. (Ogutu and Mrs A. Howard for technical assistance.

Department of Zoology,

\section{Mohamed Hyofr}

University College,

Nairobi, Kenya.

Received July 18; revised August 19, 1969.

${ }^{2}$ Amoroso, E. C., and Marshall, T. H. A., in Marshall's Physiotogy of Reproduction (edit. by Parkes, A. S.), 1, 707 (Tongmans, London, 1960).

${ }^{2}$ Lowe (McConnell), R. H., Proc. Zool. Soe. Lond., 132, 1 (1959).

${ }^{a}$ Aronson, L. R., in The Physiology of Fishes (edit. by Brown, F. M.), 2, 271 (Academic Press, New York, 1957).

4 Fryer, G., Rev. Zool. Bot. Afr., 64, 1 (1961).

5 Hyder, M., Gen. Comp, Endocrinol. (in the press).

${ }^{6}$ Hyder, M., East African Agric. For. J., 32, 178 (1966).

\section{Experimental Model for Studying the Effect of Electric Current on Bone in vivo}

SEverar groups have shown ${ }^{1-4}$ that electromechanical effects in mineralized tissues are the consequences of a classical piezoelectric phenomenon, when both direct and converse effects are present.

To correlate this biophysical phenomenon with physiological processes, many have tried to study the effects of electric current on bone in vivo. 